\title{
HOUSING PROJECTS AND CITY PLANNING
}

\author{
Alfred Bettman*
}

A proposal to clear and rebuild a slum area indicates strong dissatisfaction with the existing conditions of and in that area. The area is sordid in appearance, illkempt and obviously on the decline. Statistics of the juvenile and criminal courts, of the board of health and police department show a disproportionate amount of disease and crime occurring or originating in the area; and, certainly, the physical facts of the area, such as the character and conditions of the buildings, have had a part in producing these statistics.

The owners of the buildings are aware of these facts and results; the social workers and the building department have not permitted them to forget these facts and results. Obviously these owners do not consider it worth their while or financially possible to reconstruct or rehabilitate the buildings so as to make them more conducive to decent living conditions. The clcarance and rebuilding proposal assumes that the city government does not believe in the possibility or value of making and enforcing building regulations which would force such rehabilitation or reconstruction; and this assumption is, no doubt, correct. The causes of the evil conditions must be more complex and deep-lying than could be removed by building regulations and the orders of the building department. These beliefs of the owners and city government are corroborated by other facts of the situation. The uses of the buildings and land in the area seem to grow more spotty and mixed. Land values tend to decline. Population tends to decline. The area is abnormally unstable and depreciating in its uses, in its values, in its appearance, in everything. Something deeper and more complex is the matter with it than the mere physical conditions of the buildings.

A good mány people live in these unfit surroundings. So the jump is made to the conclusion that the thing to do is to clear the area and rebuild it with good housing; a proposal which involves an immense effort and outlay of public or private funds or both. How does anybody know, however, that the area is the appropriate place

- B.A., 1894, M.A., LL.B., 1898, Harvard. Member of firm of Moulinier, Bettman \& Hunt, Cincinnati. Practiced at Cincinnati since 1898 . General counsel, Title Guarantee \& Trust Company of Cincinnati. Member of City Planning Commission of Cincinnati and Regional Planning Commission of IJamilton County, Ohio. Member of Advisory Committec on Housing and Zoning, U. S. Department of Commerce. Governor, American City Planning Institute. Vice-President, National Conference on City Planning. Author of numerous articles and reports on city planning law, public utility franchise quea. tions, etc. 
for this effort and outlay on housing? How does anybody know whether the population decline may be due to the population trend of the whole community and not merely of the area? Might it not be probable that other parts of the city have such advantages that they will inevitably drain off the population of that area regardless of the character and conditions of its buildings, or that the transportation, school, civic, recreational and other communal facilities, which make life on a decent plane possible, are so inadequate or maldistributed or badly placed that the new housing will go the way of the old and the rehabilitated area soon become as unstable and declining as the old? Might it not be more wise to select other parts of the city for the new housing and devote the slum area to industry and other non-residential uses? New houses for old and in the same place may be too simple and superficial a remedy for a disease which has its causes in forces more deep, varied and complex than the size, character and condition of the old buildings. Before deciding on a difficult and expensive housing enterprise, ought not these forces be ascertained and traced? A disease appearing on the foot may be due to conditions in the head or heart, and revamping the foot may prove delusive.

These remarks and questions point to the conclusion that before deciding what to do with the slum area, before jumping to the conclusion that the thing to do with it is to build new housing there, the deeper and more complex sort of study of the situation which we know as city planning should be undertaken. The community needs to know what is the trend in the amount and distribution of its population and industry; what are the areas appropriate for habitation, trade, industry, recreation and civic uses, what would be a sound general allocation of the territory of the city amongst residential, trade, industrial, recreational, civic, transportation, communication and other functional uses which would tend to produce a relatively efficient, economic, healthful, convenient, decent and stable development of the city and of its various parts, including the slum area.'

An important factor in the social or material value of any structure is the appropriateness of its location for the functional service which the structure is intended to supply, and this appropriateness can be determined only by the planning of a territory or entity larger than the structure itself and of which the structure and its location form a part. Each functional part of anything derives its value and effciency from its relationships to the other functional parts; with the consequence that some degree of planning or designing the whole is necessary for an acceptable determination of the location of any part. To take a simple and obvious illustration: the extent and location of the bedroom of a house or of the living room or furnace, if that bedroom or living room or furnace is to perform its function efficiently and contribute the investment in it to the social and money value of the house, are dependent upon its relationships to the extents and locations of the other parts of the house, the halls, the kitchen and so on; and the extent and location of any part can consequently not be determined intelligently except by means of a plan or design 
of the whole house which would assign to each of these functional parts its extent and location adjusted to the extents and locations of the other functional parts. All this is equally true of the city or urban territory. The extent and location of any dwelling district cannot be determined intelligently without designing, in that general way which we know as the city plan, the extents and locations of the commercial districts, the industrial districts, the transportation facilities, the schools, the recreational spaces, the street spaces and so on; for all these are so interrelated with each other that there will be waste and instability in the investment in the dwelling district unless its interrelationships with these other uses of the land are recognized and its extent and location determined by means of some general planning or designing of the whole city.

Furthermore, the values which can be realized from the investment in a proposed housing district, whether those values be measured in terms of dollars or terms of human health, morals and decencies, as well as the stability of the district, that is, its protection against the decline of those values, are dependent not merely upon the character of the apartments or other structures which are built in the district, but on the supply of services to the people who live in those houses, some of which services may be located within the district itself and others be supplied from without the district. The inhabitants of the area will need schools, churches, fire stations, streets giving convenient and adequate access to and from other portions of the city, play spaces, everything which goes into or is required for healthful, convenient, moral and prosperous urban life. The rebuilt area can be protected against its own decline only by such a development, both of the area itself and of other portions of the city, as will tend to give the area this adequate and convenient supply of all such services; and the money and efforts required for the slum clearance and rebuilding will not be justified, unless the plan of the city assures to a reasonable degree that these services will be forthcoming.

Furthermore, the lay-out of the slum area itself is usually one of the seeds of obsolescence which is producing the decline of the area. At the time at which the old dwellings in it were built, their sizes and characters and their distribution on the land may have been appropriate to the population and uses for which they were intended; but the sizes, locations and characters of buildings appropriate for new housing may and usually will not fit at all into the existing lot and street layout of the area, and drastic changes in lot layout, involving an assembling of the land and its redistribution in an entirely different subdivision, will be necessary before any modern housing could be constructed, and this requires a different street layout, a relocation of some streets, abandonment of others and an enlargement of others, as well as relocations of or changes in the quantity of other open spaces. The replanning of the area itself is, therefore, another essential condition of a justifiable and sound rebuilding project.

We see, therefore, that before an intelligent decision can be made for the clearance 
and rebuilding of a slum area, and before any intelligent decision can be made regarding the details of the purposes, location, extent and character of the structures to be erected within the area, the procedure which we know as city planning should be followed, namely, a survey for and the making of the comprehensive plan of the city to a degree which discloses the appropriate uses of the area and whether or not housing be amongst the appropriate uses and, if so, the character and quantity, in general, of such housing; then the comprehensive planning of the portion of the city of which the area is a part, carried to that degree of detail which would indicate the extent and location of the educational, recreational, commercial, communication, transportation, civic and other types of uses which would be required for the adequate servicing of the rehabilitated area and the consequent stabilization of its housing or other classes of developments; and then the replanning of the area itself to that still greater degree of particularity which would indicate, with a fair degree of definiteness, the appropriate locations of the housing structures, business structures, civic structures, streets, recreational spaces and the other functional uses of the land within the area which would tend to stabilize and protect the buildings and other structures as those come to be planned in still greater detail and constructed by the legislative and administrative officials and the architects, contractors and builders. Unless and until these various degrees of the planning of the city and of the part of the city in which the area is located and of the area itself be done, there can be no promise that the proposed slum clearance and rebuilding will justify itself or will not simply soon start a new period of decline and depreciation of social and material values.

So far the discussion has related to the type of housing project which proposes to clear an older, more or less central and built-up area. Do these same considerations apply, however, to low-cost housing in areas still undeveloped and which are usually further removed from the center of the city? Perhaps the community can afford some guess-work, impulsive small-scale activity of that nature; but for construction on a scale which represents a grappling with and real contribution to the solution of the city's housing problem, there is need for similar planning approach and procedure; and this for the very same reasons. True, the undeveloped area has not yet exhibited the declines in values and population which in the case of the slum area demonstrated that something was wrong; but the bareness of bare land is not necessarily a sign of health, and there can be no promise whatever that the proposed housing development will be better than an incipient slum or blighted district until and unless the application of city planning techniques indicates that the area is an appropriate place for housing of the proposed character and extent, that the city plan will tend to furnish the area with the commercial, educational, recreational, transportation and civic facilities which it will need for the preservation of its vitality and for good mental, physical and moral standards of its inhabitants, and that the 
proposed layout of the area will be promotive of the protection of the area against premature decline of its human and material values.

For the reasons above outlined, a projected slum clearance or housing development may find its economic, moral and political bases in the city plan or in the results of city planning procedure, and indeed cannot possess these bases without this procedure. The legal justification may be found to be derived from the same planning procedure, and for the very same reasons; for, fundamentally, legal validity is a derivative of intellectual and moral validity. The concept "reasonable" in American jurisprudence and constitutional law means, in essence, intellectual and moral genuineness as contrasted with guesswork, slovenliness, whim, emotionalism or corruption.

Two major legal problems loom up before us in the movement for large-scale, low-cost housing. One is the question of the constitutionality, under the state and national constitutions, of raising and applying public funds and of appropriating property, by the exercise of the taxation and eminent domain powers, for any such purpose. Some of the constitutions employ the phrase "public purpose," others "public use," in their taxation and eminent domain provisions. The fact that a proposed enterprise will indirectly be of great public benefit is not sufficient, according to the judicial decisions, to warrant the exercise of the taxation or eminent domain power. The courts do not, however, interpret the expression "public purpose" or "public use" so narrowly as to limit it to actual physical occupation by a public body or official or to activities directly conducted by public officials or employees. The dividing line beween constitutional validity and invalidity lies somewhere between these extremes of indirect public benefit, on the one hand, and, on the other hand, actual physical occupation or use by public bodies, officials or employees; and, like other constitutional dividing lines, this line is capable of shifting and moving in the light of new experience and new knowledge concerning social needs.

There are authoritative decisions to the effect that the use of property by private persons for their own dwelling is not a public use; and the mere quantitative amount of such use, the mere largeness of the scale of that use, may not, in and of itself, prove to be sufficient to move the constitutional dividing line as far or as speedily as we deem necessary for good housing. If, however, the results of a careful and thorough city planning investigation and procedure demonstrate that a proposed clearance or housing project is justified as a matter of good city layout and development, and that the project is so interrelated with the city's own present and prospective investments in public schools and other public buildings, in playground and other recreational spaces, and in public streets and other public utilities for communication, transportation, sanitation and so on, that the sound, economic and efficient locating and constructing of these public buildings, utilities and grounds are interdependent with and upon the housing development; and if, further, the im- 
portance of the proposed new housing from the point of view of the reduction of disease and delinquency and promotion of a decent quality of living be shown, and further that the necessary housing is not likely to be furnished by private capital or through the ordinary processes of private finance, trade and industry, then the city planning procedure may be found to have furnished sufficient proof that the clearance and housing enterprise will not merely benefit the public indirectly, but will be a direct public purpose or public use in the constitutional sense.

The cost of the property to be acquired for a slum clearance and housing development has, of course, a rather decisive effect upon the success of the effort to translate the project into accomplishment and upon the social and financial consequences of that accomplishment. This problem of property-costs turns somewhat upon the principles of law governing compensation in actions for the appropriation of private property for public use. The general principle is that the owner is to be paid the value of his property. What factors of value will be recognized by the courts and what are the modes of proof of those factors are questions which present the second legal problem or obstacle to be solved or surmounted on the road to good housing. The courts hold that the land is to be valued according to the use or uses for which it is appropriate. In the trial of a condemnation case, the experts employed by the property owner allow their fancies to roam freely, speculatively and imaginatively on this subject. Physically a piece of land is appropriate for almost any kind of use, residential, commercial, civic, industrial, recreational or what not. In that sense, land in the Desert of Sahara would be appropriate for a central heating plant. Mere physical appropriateness cannot be the test, but rather the appropriateness of the location for a functional use or uses. Little thought ought to be necessary to realize that the appropriate functional use of the land in question is dependent on the appropriate functional uses of other land located not only in the same neighborhood but in other parts of the city. The entire land within the city cannot be appropriate for dwelling purposes; for the people of the city cannot occupy more dwelling space than will house all of the population and they need other uses of the land, such as streets and stores and parks and schools. The appropriateness of a specific piece of land for dwelling purposes results from or is inextricably bound up with the appropriateness of other locations for streets and stores and factories and parks and schools and the other uses which go to make up a city; and one cannot know which areas or spaces are appropriate for the dwelling uses without knowing something about the location of those appropriate for the other uses. Obviously the same planning data and considerations and principles which result in the allocation of an area to low-cost housing use furnish reasonable (that is, non-guesswork and non-speculative) and strong evidence that the land of that area is appropriate for low-cost housing and that the compensation to be paid should be measured accordingly.

The story is told of a wealthy but rather parsimonious man who, strolling along 
the street, met his friend, a distinguished and successful lawyer. Chattily he put a question of law to the lawyer, who then and there answered it. The question was not purely academic; for the rich man had on his hands a situation which required him to make a decision turning on the answer to that very question of law. He proceeded to follow the advice, and thereby suffered a considerable financial loss. Thereafter, on again meeting his lawyer friend, he complained about the advice which had resulted so adversely. On being asked how much he had paid for the advice, he answered that he had paid nothing whatever for it; whereupon he was informed that perhaps the advice which he had received was worth exactly what he had paid for it. The same measure of value may apply to the advice here given; but, for whatever it may prove to be worth, the suggestion is hereby ventured that communities contemplating slum clearance and large-scale housing and, therefore, having to prepare for determinations, amicable or contested, of the amounts to be paid for the necessary lands, may find the time, effort and money spent on city planning procedure to be a shrewd and productive investment.

Which would be as it should be. For the community ought not place its housing in inappropriate areas and ought to be prepared to so control the development of its territory as to protect the housing against premature decline and decay and to furnish the services which will be needed for that protection. This means planning the city's lay-out to the full extent necessary for determining the appropriate housing areas and for assuring that protection. The future cannot be known or estimated with a certainty which eliminates all risks. But unquestionably the slums and blighted districts have resulted to some extent from past planlessness, that is, from deteriorating influences, some of which were avoidable through planning. We can reduce the guess-work and speculative factors in the development of our urban areas. These factors, including speculative land values, have contributed to the social evils which slums and bad housing symbolize and produce; and to the extent that a community has the intelligence and will-power to apply, with thoroughness and conscientiousness, city planning principles and methods and thereby reduce the speculative factors, it is entitled to the benefits of its action. 